\title{
Autonomic dysfunction and migraine: Assessed by time series analysis of heart rate variability
}

\author{
Tahmina Akter ${ }^{1}$, Sultana Ferdousi ${ }^{2}$
}

\begin{abstract}
Background: Migraine is associated with autonomic nervous system dysfunction with reduced heart rate variability (HRV). Objective: To assess the cardiac autonomic function in migraine patients. Methods: This prospective study was carried out in the Department of Physiology, Bangabandhu Sheikh Mujib Medical University during 2013. Cardiac autonomic nerve function of 60 newly diagnosed untreated migraine patients aged 15-30 years, both male and female was assessed by analyzing time domain measures of HRV. Thirty age, sex, BMI matched healthy control were also assessed and compared. The diagnosed migraine patients were selected from the out patient department of Neurology, BSMMU, Dhaka. The HRV parameters were recorded by a 4 active channels, RMS polyrite-D. For statistical analysis, Independent Sample t-test was used. Results: Resting pulse rate, mean heart rate were found significantly higher and mean R-R interval, SDNN, RMSSD were significantly lower in all patients with migraine than those of healthy control. Conclusion: Autonomic dysfunction characterized by impaired cardiac vagal tone was associated with migraine.
\end{abstract}

Key words: RMSSD, SDNN, HRV Migraine

\author{
J Bangladesh Soc Physiol. 2017, December; 12(2): 57-60 \\ For Authors Affiliation, see end of text. \\ http://www.banglajol.info/index.php/JBSP
}

\section{Introduction}

$\mathbf{M}$

igraine is a primary headache disorder characterized by headache and hypersensitivity to sensory stimuli ${ }^{1}$.

World health organization (WHO) has ranked it $7^{\text {th }}$ most disability causing disorder characterized by chronic neurological disorder associated with autonomic dysfunction ${ }^{2-3}$. The incidence of migraine peaks between 15 years and 24 years of age and the prevalence is highest among persons between the ages of 35 to 45 years ${ }^{4}$.

Research evidence showed some autonomic dysfunction related symptoms appear before and during the attack of a migraine headache. Symptoms include nausea, vomiting, diarrhoea, cuntaneous

Received 28 July 2017; Accepted 04 August. 2017 vasodilatation (flushing), vasoconstriction (pallor), piloerection, sweating and diaphoresis 5 .

HRV is a sensitive and non invasive tool capable of assessing individual sympathetic and parasympathetic activity. In clinical practice, both time domain and frequency method for short term HRV analysis is used for the assessment of autonomic regulation of cardiovascular function 6 .

Though several studies investigated the autonomic function in migraine patients but the results were controversial and inconclusive. Some authors reported increased para-sympathetic function and sympathetic hypo or hyper function whereas others emphasized parasympathetic hypofunction ${ }^{3,6-8}$.

No study has investigated in Bangladesh the potential of cardiac autonomic dysfunction due 
to migraine. This study aimed to investigate cardiac autonomic nerve function by analyzing the time series data of heart rate variability to find out the probability of cardiac autonomic dysfunction in migraine patients.

\section{Methods}

This prospective study was carried out to observe the cardiac autonomic activity by assessing some time domain measures of HRV in 60 newly diagnosed migraine patients aged 15 30 years in the department of physiology, Bangabandhu Sheikh Mujib Medical University (BSMMU), Shahbag, during 2013. For comparison 30 apparently healthy subjects were also studied as control. These patients were selected from the out patients department of neurology, BSMMU. Migraine patients with history of taking anti migraine drugs, previously diagnosed as hypertension, diabetes mellitus, ischaemic heart diseases, renal disease, psychic disorder and smoking were excluded from the study. After explaining, informed written consent was taken from each subject. The protocol of this study was approved by the Institutional Review Board of BSMMU. Then immediately after enrollment, the subject was advised to follow some instruction in the previous night of HRV test day. They were advised to report in the department of Physiology at about 9:00 am with light breakfast and without tea or coffee on the test day. HRV data were recorded before initiating treatment with any antimigraine drugs. All HRV test was done in the autonomic nerve function laboratory in the department of physiology BSMMU. The subject was kept in supine position in a bed for 15-20 minutes in a controlled laboratory environment. Then all preparations for recording of the HRV parameters were made by connecting lead II to the channel of ECG of a data acquisition device Polyride D (RMS India) and a 5 minutes short term recording ECG was taken in resting position. Values of Mean heart rate, Mean R-R interval, Max/Min R-R interval, SDNN, RMSSD were displayed by polygraph software analysis.

For statistical analysis independent sample $\phi t c$ test was performed. $\mathrm{p}<0.05$ was taken as level of significance.

\section{Results}

The anthropometric parameters of the subjects are presented in Table I.

The mean values of pulse rate, mean heart rate were significantly higher $(\mathrm{p}<0.001)$ and mean RR interval, SDNN and RMSSD were significantly lower $(\mathrm{p}<0.001)$ in migraine patients than control (Table II and Table III).

Table I: Age and BMI in different groups $(n=90)$

\begin{tabular}{lcc}
\hline Parameters & $\begin{array}{c}\text { Control } \\
(\mathrm{n}=60)\end{array}$ & $\begin{array}{c}\text { Migraine } \\
(\mathrm{n}=30)\end{array}$ \\
\hline Age $($ Years $)$ & $20.4 \pm 0.70$ & $22.2 \pm 0.70$ \\
BMI $(\mathrm{Kg} / \mathrm{m} 2)$ & $24.32 \pm 0.50$ & $23.79 \pm 0.50$ \\
\hline
\end{tabular}

Data were expressed as Mean \pm SE. Statistical analysis were done by Independent sample t-test.

Table II: Resting Pulse rate and BP in all subjects at baseline $(\mathrm{n}=90)$

\begin{tabular}{lcc}
\hline Parameters & $\begin{array}{c}\text { Control } \\
(\mathrm{n}=30)\end{array}$ & $\begin{array}{c}\text { Migraine } \\
(\mathrm{n}=60)\end{array}$ \\
\hline Pulse (beat/min) & $68.37 \pm 0.80$ & $79.2 \pm 1.55^{* * *}$ \\
SBP $(\mathrm{mm}$ of $\mathrm{Hg})$ & $109.67 \pm 1.42$ & $110.17 \pm 1.47$ \\
DBP $(\mathrm{mm}$ of $\mathrm{Hg})$ & $67.33 \pm 1.04$ & $68 \pm 1.35$ \\
\hline
\end{tabular}

Data were expressed as Mean \pm SE. Statistical analysis were done Independent sample t-test $* * *=\mathrm{p}<0.001$

Table III: Time domain measures of HRV in different groups $(\mathrm{n}=90)$

\begin{tabular}{lcc}
\hline Parameters & $\begin{array}{c}\text { Control } \\
(\mathrm{n}=30)\end{array}$ & $\begin{array}{c}\text { Migraine } \\
(\mathrm{n}=60)\end{array}$ \\
\hline $\begin{array}{l}\text { Mean heart rate } \\
\text { (beats/min) }\end{array}$ & $69.13 \pm 1.22$ & $85.2 \pm 1.35^{\text {*** }}$ \\
$\begin{array}{l}\text { Mean R-R interval } \\
\text { (beats/min) }\end{array}$ & $0.87 \pm 0.02$ & $0.71 \pm 0.02^{* * *}$ \\
SDNN $(\mathrm{ms})$ & $161.95 \pm 6.51$ & $47.16 \pm 1.46^{* * *}$ \\
RMSSD $(\mathrm{ms})$ & $41.81 \pm 1.1$ & $35.97 \pm 0.9^{* * *}$ \\
\hline
\end{tabular}

Data were expressed as Mean \pm SE. Statistical analysis were done Independent sample t-test $* * *=p<0.001$ 


\section{Discussion}

The present study assessed cardiac autonomic nerve function activity in newly diagnosed migraine patient before medication by analysis of time domain measures of HRV and compared with those of healthy control. Simple time domain measures including mean R-R interval and mean heart rate reflects cardiac vagal activity and SDNN and RMSSD are indices of general autonomic balance ${ }^{6,9-10}$.

In this study, resting pulse rate, mean HR, were found significantly higher in newly diagnosed migraine patients than healthy control. Similar results were found by Cortelli et al. in migraine patients ${ }^{11}$.

In the present study, lower cardiac vagal modulation indicated by lower values of time domain measures agrees to other investigators 11-14. Similar results in lower mean R-R interval in all newly diagnosed migraine patients compared to healthy controls were comparable to the findings of several others investigators ${ }^{7,15-16}$.

The reduced cardiac vagal modulation in the newly diagnosed migraine patients of the present series is shared by several groups of researchers ${ }^{16-20}$.

Perciaccante et al. assessed heart rate variability in patient with active migraine and with aura. They reported that lower value of SDNN is associated with sympathetic hyperactivity ${ }^{21}$.

Tabata and his colleagues observed RMSSD in migraine patients were significantly lower than those of control which indicates parasympathetic hypo function in migraineurs 22 .

In the present study, values of HRV parameters in healthy control group were comparable to those reported by the several groups of investigators from different countries ${ }^{13,23}$ and also from our country 12,14 .

The exact mechanisms of changes in cardiac autonomic nerve activities in migraine are not yet completely understood. Various investigators probing the cause of accompanying autonomic symptoms in migraine attack have mentioned about the dysfunction of the autonomic nerve activity in patients with migraine $e^{7,15,21-22,24-25}$.

Literatures suggested migraineurs have increased hypothalamic functional connectivity with the sympathetic and parasympathetic processing than the healthy control. This altered hypothalamic functional connectivity may cause autonomic dysfunction in migraine 22 .

\section{Conclusion}

The results of this study concluded that autonomic dysfunction with impaired cardiac vagal tone is associated with migraine.

\section{Conflict of interest None}

\section{Acknowledgement}

This study received a research grant from the Ministry of Education of Bangladesh from its project of research grant for higher education.

\section{Author affiliation}

1. Tahmina Akter, Assistant professor, Department of Physiology, US-Bangla medical college, Bangladesh. Email: tahminakmc0306@gmail.com.

*2. Sultana Ferdousi, Associate Professor, Department of Physiology, Bangabandhu Sheikh Mujib Medical University (BSMMU), Bangladesh. Email:sferdo usiratna@gmail.com; sferdousiratna@bsmmu.edu.bd

*For correspondence

\section{References}

1. Headache classification committee of the international headache society. The international classification of headache disorders: $2^{\text {nd }}$ edition. cephalagia. 2004; 24: 9-160.

2. Alstadhaug KB. Migraine and the hypothalamus. Cephalalgia. 2009;29:809-17.

3. Vijayalakshmi I, Shankar N, Bhatia MS, Saxena A, Gupta R. Evaluation of neurophysiological parameters: autonomic status and acute pain perception in migraneurs. Delhi psychiatry journal. 2010;13 (1).79-85

4. Stewart WF, Wood C, Reed ML, Roy J, Lipton RB. Cumulative lifetime migraine incidence in women and men. Cephalgia.28(11):1170-78. 
5. Turner IM, Colombo J. Aurtonomic dysfunction in migraine.[Internet]2004. [cited on April 14] Available from:www.anshrv.com/ chronic/ turnermigrainecasestudy2s.pdf

6. Mallik M and Task force of the European Society of Cardiology and the North American Society of Pacing and Electrophysiology, Heart Rate Variability. Standards of measurement, physiological interpretation and clinical use. Euro Heart J. 1996 ; 17: 354-8.

7. Samir H, Rashad H, Zakaria Y, Hassan R, Wahab FAE. Assesment of cardiovascular autonomic functions in migrainous patients. Egypt $\mathrm{J}$ Neurol. Psychiat. Neurosurg, 2006; 43(1): 179-86.

8. Augül R, deniz O, Orhan A, Kocak N, Kaya MD, Ulvi H. R-R interval variation in migraine patiernts. Eastern J med 2006; 11: 1-6.

9. Perotkar SJ. Migraine: A chronic sympathetic nervous system disorder. Headache 2004; 44: 5363.

10. Evrengül H, Dursunoglu D, Cobankara V, Polat B, Seleci D, Kabukeu S, Kaftan A, Semiz E, Kilic M. Heart rate variability in patients with rheumatoid arthritis. Rheumatol Int. 2004; 24:198-202.

11. Cortelli P, Pierangeli G, Parchi P, Contin M, Baruzzi A, Lugaresi E. Autonomic nervous system function in migraine without aura. Headache. 1991;31:45762 .

12. Nayem M. Characterization of autonomic nerve functions in patients with Irritable Bowel Syndrome. [Thesis] 2011 [Dhaka (Bangladesh)]: BSMMU.

13. Alyan Kacmaz OF, Ozdemir O , Maden O, Topaloglu S , Ozbakir C, Metin F , Karadede A , Ilkay E. Effects of cigarette smoking on heart rate variability and plasma $\mathrm{N}$-terminal pro-B-type natriuretic peptide in healthy subjects: is there the relationship between both markers? Ann Noninvasive Electrocardiol 2008; 13:137-144.

14. Elmenshawy E, Sakr S. Autonomic Dysfunction in Migraine; What Do We Need to Know? Egypt J Neurol Psychiat Neurosurg 2009 ; 46(2): 489-96

15. Hsu LKG, Crisp AH, Kalucy RS et al: Early morning migraine: Nocturnal plasma levels of catecholamines tryptophan, glucose and free fatty acids and sleep encephalographs Lancet 1977; 2:447-51.
16. Hsu LKG, Crisp AH, Kalucy RS et al: Nocturnal plasma levels of catecholamines tryptophan, glucose and free fatty acids and the sleeping electroencephalographs of subjects experiencing early morning migraine. In Greene R (ed). Current concepts in migraine Research. New York: Raven Press; 1978. pp 121-130.

17. Havanka-Kanniainen H, Tolonen U ,Myllylä W.Cardiovascular reflexes in young migraine patients. Headache. 1986; 26:420-24.

18. Hsu LKG, Crisp AH, Kalucy RS et al: Nocturnal plasma levels of catecholamines tryptophan, glucose and free fatty acids and the sleeping electroencephalographs of subjects experiencing early morning migraine. In Greene R (ed). Current concepts in migraine Research. New York: Raven Press;1978. pp 121-130

19. Pogacnik T, Sega S, Pecnik B, Kiauta T. Autonomic function testing in patients with migraine. Headache. 1993; 33:545-50.

20. Moulton EA, Becerra L, Maleki N, Pendse G, Tully $\mathrm{S}$, et al. Painful heat reveals hyperexcitability of the temporal pole in interictal and ictal migraine States. Cereb Cortex 2011; 21: 435-48. doi: 10.1093/cercor/bhq109

21. Perciaccante A, Fiorentini A, Valente R, Granata M, Tubani L. Migraine and heart rate variability.Arch Intern Med 2007;167(20):2264. doi:10.1001/archinte. 167.20.2264-a

22. Tabata M, Burioka N, Takeshima T. A 48-Hour holter ECG study in migraineurs during usual daily activities. Yonago Acta medica 1999; 42:61-8.

23. Cagirci G, Cay S, Karakurt O, Eryasar N, Kaya V, Canga A, Yesilay AB, Kilic H, Topaloglu S, Aras D, Demir AD, Akdemir R. Influence of heavy cigarette smoking on heart rate variability and heart rate turbulence parameters. Ann Noninvasive Electrocardiol 2009;14(4):327-32

24. Tabata M, Takeshima T, Burioka N, Nomura T, Ishizaki K, Mori N, Kowa H, Nakeshima K. Cosinor analysis of heart rate variability in ambulatory migraineurs. Headache 2000; 40(6):457-63.

25. Havanka-Kanniainen H, Tolonen U, Myllyla VV. Autonomic dysfunction in migraine :a survey of 188 patients. Headache 1988; 28: 465-70. 